\title{
Occupational Performance and Affective Symptoms for Patients with Depression Disorder
}

\author{
Åsa Daremo, ${ }^{1,2}$ Anette Kjellberg, ${ }^{2}$ and Lena Haglund ${ }^{2}$ \\ ${ }^{1}$ Department of Psychiatry, University Hospital, 58185 Linköping, Sweden \\ ${ }^{2}$ Department of Social and Welfare Studies, Faculty of Health Sciences, Linköping University, Linköping, Sweden \\ Correspondence should be addressed to Åsa Daremo; asa.daremo@regionostergotland.se
}

Received 27 August 2014; Revised 17 January 2015; Accepted 19 January 2015

Academic Editor: Raphael J. Braga

Copyright (c) 2015 Åsa Daremo et al. This is an open access article distributed under the Creative Commons Attribution License, which permits unrestricted use, distribution, and reproduction in any medium, provided the original work is properly cited.

\begin{abstract}
The aim of this study was to describe recovering over time in occupational performance and in affective symptoms for patients with depression disorder by using different assessments and methods for collecting data. A longitudinal design with data collections on repeated occasions was used. The Occupational Circumstances Assessment Interview and Rating Scale and Occupational SelfAssessment were used for measuring occupational performance, and for affective symptoms, a Comprehensive Psychopathological Rating Scale Self-Assessment was used. Fourteen patients with depression disorder were included in the study. The result indicates that affective symptoms improve earlier than occupational performance. Furthermore, self-assessment seems to reflect more improvement to the patient than interview-based assessment. Different kinds of assessment and different kinds of data collection methods seem to facilitate the understanding of the patients recovering. In addition habituation was the most important item for the patients to manage. One implication for practice is that patients may need an extended period of treatment supporting occupational performance.
\end{abstract}

\section{Introduction}

Depression is a common mental disorder and affects people of all ages. The disorder is so common that most people have either experienced it themselves or have a near relative who has suffered from it [1]. Depression is the most common reason for ill health, lost productivity, and work disability in the world. It is the leading cause of disability as measured by Years Lived with Disability (YLD) and was the fourth leading contributor to the global burden of disease by Disability Adjusted Life Years (DALY) in 2000. By the year 2020, depression is projected to reach second place in the ranking of DALYs calculated for all ages and for both sexes, and about 121 million people worldwide are affected today [2]. The picture in Sweden does not differ from the global perspective [3].

DSM-V states that at least two of the symptoms of depression, lack of energy, and reduced activity must have been experienced for at least two weeks in order for a diagnosis of depression to be given. When suffering depression, the patient lacks self-esteem, has feelings of guilt, and experiences hopelessness and meaninglessness. Self-confidence is reduced and the low self-esteem is like a loss of inner certainty and power [4]. All these symptoms have an impact on occupational performance. Since the cognitive, the behavioural, social, and physiological areas are affected, most patients have difficulties performing daily activities. Daily routine activities such as home care, meal preparation, and self-care are often affected, as well as the ability to interact with others [5]. Furthermore, the area of work often presents many problems for adults with depression [6].

The Model of Human Occupation (MOHO) attempts to explain how humans are motivated toward and choose to do things in their patterns of everyday life and in their individual capacities. There is evidence that $\mathrm{MOHO}$ has become the most widely used occupation-focused model; about $80 \%$ of occupational therapists worldwide have indicated that they use MOHO in everyday practice $[7,8]$. In the model, interrelated components such as volition, habituation, and performance capacity are understood in relation to the 
TABLE 1: Demographic data for the patients and the number of assessments.

\begin{tabular}{|c|c|c|c|c|c|c|c|}
\hline $\begin{array}{l}\text { Patient } \\
n=14\end{array}$ & Sex & Age & Treatment period & $\begin{array}{c}\text { OCAIRS-S } \\
n=46\end{array}$ & $\begin{array}{c}\text { OSA } \\
n=75\end{array}$ & $\begin{array}{c}\text { CPRS-S-A } \\
n=73\end{array}$ & $\begin{array}{c}\text { Total assessments } \\
n=194\end{array}$ \\
\hline 1 & Woman & 29 & 4 months and 3 weeks & 5 & 8 & 8 & 21 \\
\hline 2 & Man & 47 & 2 months and 1 week & 3 & 2 & 2 & 7 \\
\hline 3 & Woman & 49 & 8 months and 2 weeks & 7 & 12 & 12 & 31 \\
\hline 4 & Woman & 49 & 7 months & 4 & 12 & 12 & 28 \\
\hline 5 & Man & 59 & 2 months & 3 & 5 & 4 & 12 \\
\hline 6 & Man & 24 & 26 days & 2 & 2 & 1 & 5 \\
\hline 7 & Woman & 18 & 5 months and 2 weeks & 4 & 8 & 8 & 20 \\
\hline 8 & Man & 45 & 1 month & 2 & & & 2 \\
\hline 9 & Man & 48 & 5 months & 3 & 6 & 6 & 15 \\
\hline 10 & Man & 58 & 2 months and 1 week & 3 & & & 3 \\
\hline 11 & Man & 27 & 25 days & 1 & 2 & 2 & 5 \\
\hline 12 & Woman & 63 & 7 months and 3 weeks & 2 & 8 & 8 & 18 \\
\hline 13 & Woman & 62 & 3 months & 4 & 5 & 5 & 14 \\
\hline 14 & Woman & 28 & 2 months and 1 week & 3 & 5 & 5 & 13 \\
\hline
\end{tabular}

influence of the physical and social environments on the occupation. Volition refers to the motivation for occupation and it reflects, for example, the individual's interest and values. Habituation refers to the process by which occupation is organized into routine behaviour in daily life, and performance capacity refers to the ability to do things. As a function of the interaction between the personal components (volition, habituation, and performance capacity) and the environment, skills are used; these skills are observable and goal-directed actions. Several structured assessments have been developed for use with MOHO. They all reflect years of development and have been studied and worked up to enhance their psychometric status and practical usefulness [9].

Furthermore, it is important to clarify what the patient wants and needs to do and measure the actual performance. This can be done with different data collection methods such as self-assessment, interviews, or observation. To our knowledge no other studies have been performed using a longitudinal design in combination with using evidence based measures including self-assessment and interviewing patients with depressions. In addition comparing occupational performance and affective symptoms has not been investigated. Therefore the aim is to describe recovering over time in occupational performance and affective symptoms for patients with depression by using different methods for collecting data and assessments.

\section{Method}

The study attempted to gain a longitudinal perspective [10], with data collections on repeated occasions. To investigate change over time in occupational performance, the Occupational Circumstances Assessment Interview and Rating Scale (OCAIRS) [11] and Occupational Self-Assessment (OSA) [12] were used, and for affective symptoms, the Comprehensive
Psychopathological Rating Scale Self-Assessment (CPRS-SA) [13] was used.

In total 45 patients were treated in psychiatric institutional care in two different hospitals, located in the southern part of Sweden. Both hospitals are located in rural areas. All patients were diagnosed by the medical doctor at the ward. The inclusion criteria for the study were depression with suicidal behaviour according to DSM-V [4]. An inquiry about participation in the study was consecutively asked, the first week at the psychiatric ward, by the occupational therapist or the occupational therapist assistant belonging to the ward.

Eighteen patients gave informed consent to participate and 14 patients completed the study.

The 14 patients included seven women and seven men. The ages ranged between 18 and 63 years, with an average age of 39 years. The treatment periods varied from 25 days to eight and a half months (mode = two months and one week) and during this period the patients could be treated in both institutional care and noninstitutional care (Table 1). The Regional Ethical Review Board in Linköping, Sweden, approved the study.

\subsection{Data Collection}

2.1.1. Assessments. The OCAIRS, which is a MOHO-based assessment, was originally developed for use in acute psychiatric settings [9]. It is often used as an initial interview and it collects information about the patient's participation and ability to manage daily activities. OCAIRS is a semistructured interview. There is a structure to the type of information that is gathered and how it is interpreted. The OCAIRS uses a 4point rating scale (Table 2) [11, 14]. The development of the OCAIRS started in 1989 and several studies examining the quality of the assessment have been completed. These studies provide evidence of reliability and concurrent validity [1416]. The Swedish version of the assessment which is used in this study is designated OCAIRS-S. 
TABLE 2: Grades in the rating scales.

\begin{tabular}{|c|c|c|c|}
\hline & Grades & $\begin{array}{l}\text { Number } \\
\text { of items }\end{array}$ & $\begin{array}{l}\text { Score } \\
\text { interval }\end{array}$ \\
\hline \multirow{4}{*}{ OCAIRS-S } & $0=$ "Competent" & \multirow{4}{*}{12} & \multirow{4}{*}{$0-36$} \\
\hline & $\begin{array}{l}1=\text { "Some } \\
\text { difficulties/challenges" }\end{array}$ & & \\
\hline & $\begin{array}{l}2=\text { "Explicit } \\
\text { difficulties/challenges" }\end{array}$ & & \\
\hline & $\begin{array}{l}3=\text { "Problems in highly } \\
\text { restrictive" }\end{array}$ & & \\
\hline \multirow{3}{*}{ OSA } & $0=$ "I do it well" & \multirow{3}{*}{29} & \multirow{3}{*}{$0-58$} \\
\hline & 1 = "I manage it" & & \\
\hline & $2=$ "I have a problem with it" & & \\
\hline \multirow{4}{*}{ CPRS-S-A } & $0=$ "I often feel calm" & \multirow{4}{*}{19} & \multirow{4}{*}{$0-114$} \\
\hline & $\begin{array}{l}2 \text { = "Sometimes I have } \\
\text { unpleasant feelings of anxiety" }\end{array}$ & & \\
\hline & $\begin{array}{l}4=\text { "I often have feelings of } \\
\text { anxiety, which sometimes can } \\
\text { be very strong, and which I } \\
\text { make an effort to master" }\end{array}$ & & \\
\hline & $\begin{array}{l}6=\text { "I have terrible, protracted } \\
\text { or unbearable anxiety feelings" }\end{array}$ & & \\
\hline
\end{tabular}

The OSA, which also is a MOHO-based assessment, is an evaluation tool and an outcome measurement. The OSA is a two-part self-rating form. It is designed to capture patients' perceptions of their own occupational competence and of the occupations they consider important. In this study, version 1 was used, and this has a two-part rating form, with a 3-point rating scale in each part (Table 2). First, the patient responds to items about his occupational competence and then indicates the importance of each of these items. When the patient has responded to the questions about competence and values he can go on to choose the areas he would most like to change. In this study the patients did not carry out this last step.

Several international studies have been conducted on the OSA, confirming that the OSA items and ratings (competence and value) can be used as valid and reliable measures of a patient's occupational competence and the value of occupation $[12,17]$. In this study, a Swedish version of the OSA is used that is called "Min Mening."

CPRS-S-A is a self-rating scale for affective syndromes. The assessment was developed on the basis of the original CPRS from 1978 [18]. The resulting subscale, for affective syndromes (CPRS-A), was then revised to a self-rating format (CPRS-S-A) [19]. CPRS-S-A covers depression, anxiety, and obsessional symptoms. The purpose of the assessment is to give a detailed picture of the patient's present sense of his condition. The patient grades how he has felt over the previous three days. CPRS-S-A has a 7-point rating scale (Table 2). The assessment has been used frequently since the end of 1970 in different studies and has shown good values concerning reliability and clinical usefulness $[19,20]$.

2.2. Procedure. The patients were initially interviewed with the OCAIRS-S and the patients also filled in the self-rating assessments, OSA and CPRS-S-A. Occupational therapists performed the interviews with OCAIRS-S; they had several years of experience in the area of psychiatric care.

After the first occasion the patient filled in these two selfrating assessments every fortnight and the interview using the OCAIRS-S was repeated every month until the patient was discharged.

The interviews were conducted at the hospital or in the patient's home or, in exceptional cases, by telephone. The interviews lasted from 30 to 60 minutes. The self-rating assessments (OSA, CPRS-S-A) were given to the patient at the hospital or sent by post if the patient was treated as an outpatient. The total number of assessments for each patient is presented in Table 1. In total, 194 assessments-on average 14 (range 3-31) assessments per patient-were performed during the period.

2.3. Data Analysis. For identifying intraindividual differences for each patient the sum scores from each occasion from OCAIRS-S, OSA, and CPRS-S-A were compared. The differences for each patient over time are based on a period of four months since most of the patients were discharged after that time (Table 3). In addition an investigation was also made of whether or not there were changes over time regarding occupational performance measured by OCAIRS$S$ and OSA and symptoms measured by CPRS-S-A. These changes were investigated for each patient.

\section{Results}

Nine of the 14 patients (9/14) showed a positive trend during the treatment period (Table 3 ). For some of these nine patients, their score constantly changed in a positive way and for some patients the scores varied during the treatment period. However, all of these nine patients (patients 1, 4, 5, $6,7,9,11,13$, and 14) changed in a positive way, both in occupational performance and in affective symptoms, when the first and the last occasions were compared.

No clear trend could be seen for two of the 14 patients (patients 2 and 12) since the scores shifted and there was no homogenous pattern between the three assessments. Patient number 3 had a negative development during the treatment period related to occupational performance. Furthermore, missing data was frequent for two of the patients (patients 8 and 10).

Occupational performance was measured with OCAIRS$S$ and OSA. In total, the results showed that the patients still had problems in occupational performance after discharge. Comparing between the first and the last occasion the patients improved more when measuring with the selfassessment OSA ( 8 of 14 patients) than when the occupational therapist interviewed the patient with OCAIRS-S (6 of 14 patients) (Table 3).

The study indicates that patients can have low scores measured with the CPRS-S-A, that is, few symptoms, but still have problems with their occupational performance. The sum score of CPRS-S-A indicates an earlier improvement than the sum score based on OCAIRS-S and OSA. Less affective 
TABLE 3: Sum scores of the different assessments for each patient $(n=14)$.

\begin{tabular}{lccccccccccccccc}
\hline \multirow{2}{*}{ Patient } & \multicolumn{3}{c}{ Occasion 1 } & \multicolumn{4}{c}{ Occasion 2 } & \multicolumn{3}{c}{ Occasion 3} & \multicolumn{3}{c}{ Occasion 4} \\
& OCAIRS & OSA & CPRS & OCAIRS & OSA & CPRS & OCAIRS & OSA & CPRS & OCAIRS & OSA & CPRS \\
\hline 1 & 16 & 39 & 53 & $12(\mathrm{I})$ & $37(\mathrm{I})$ & $46(\mathrm{I})$ & $11(\mathrm{~S})$ & $29(\mathrm{I})$ & $27(\mathrm{I})$ & $9(\mathrm{I})$ & $38(\mathrm{R})$ & $36(\mathrm{R})$ \\
2 & 6 & 12 & 18 & $12(\mathrm{R})$ & $15(\mathrm{R})$ & $25(\mathrm{R})$ & $11(\mathrm{~S})$ & - & - & $\mathrm{d}$ & $\mathrm{d}$ & $\mathrm{d}$ \\
3 & 12 & 24 & 61 & $17(\mathrm{R})$ & $29(\mathrm{R})$ & $44(\mathrm{I})$ & $10(\mathrm{I})$ & $30(\mathrm{R})$ & $66(\mathrm{R})$ & $15(\mathrm{R})$ & $26(\mathrm{I})$ & $46(\mathrm{I})$ \\
4 & 14 & 53 & 54 & $10(\mathrm{I})$ & $41(\mathrm{I})$ & $37(\mathrm{I})$ & $16(\mathrm{R})$ & $49(\mathrm{R})$ & $39(\mathrm{R})$ & $13(\mathrm{I})$ & $49(\mathrm{I})$ & $30(\mathrm{I})$ \\
5 & 16 & 32 & 35 & $4(\mathrm{I})$ & $19(\mathrm{I})$ & $17(\mathrm{I})$ & $5(\mathrm{~S})$ & $7(\mathrm{I})$ & $14(\mathrm{I})$ & - & - & $14(\mathrm{~S})$ \\
6 & 11 & 38 & 43 & $11(\mathrm{~S})$ & $36(\mathrm{I})$ & $27(\mathrm{I})$ & $\mathrm{d}$ & $\mathrm{d}$ & $\mathrm{d}$ & $\mathrm{d}$ & $\mathrm{d}$ & $\mathrm{d}$ \\
7 & 10 & 49 & 51 & $10(\mathrm{~S})$ & $30(\mathrm{I})$ & $27(\mathrm{I})$ & $0(\mathrm{I})$ & $29(\mathrm{I})$ & $8(\mathrm{I})$ & - & $25(\mathrm{I})$ & $6(\mathrm{I})$ \\
8 & 1 & - & - & $3(\mathrm{R})$ & - & - & $\mathrm{d}$ & $\mathrm{d}$ & $\mathrm{d}$ & $\mathrm{d}$ & $\mathrm{d}$ & $\mathrm{d}$ \\
9 & 13 & 31 & 80 & $16(\mathrm{R})$ & $38(\mathrm{R})$ & $81(\mathrm{~S})$ & - & $34(\mathrm{I})$ & $69(\mathrm{I})$ & $10(\mathrm{I})$ & $29(\mathrm{I})$ & $43(\mathrm{I})$ \\
10 & 9 & - & - & $5(\mathrm{I})$ & - & - & $7(\mathrm{R})$ & - & - & $\mathrm{d}$ & $\mathrm{d}$ & $\mathrm{d}$ \\
11 & 6 & 39 & 24 & - & $37(\mathrm{I})$ & $22(\mathrm{I})$ & $\mathrm{d}$ & $\mathrm{d}$ & $\mathrm{d}$ & $\mathrm{d}$ & $\mathrm{d}$ & $\mathrm{d}$ \\
12 & $\mathrm{x}$ & 34 & 43 & - & $28(\mathrm{I})$ & $46(\mathrm{R})$ & 5 & $51(\mathrm{R})$ & $45(\mathrm{~S})$ & $0(\mathrm{I})$ & $33(\mathrm{I})$ & $43(\mathrm{I})$ \\
13 & 22 & 37 & 60 & $19(\mathrm{I})$ & $42(\mathrm{R})$ & $34(\mathrm{I})$ & $15(\mathrm{I})$ & $35(\mathrm{I})$ & $18(\mathrm{I})$ & $14(\mathrm{I})$ & $33(\mathrm{I})$ & $19(\mathrm{~S})$ \\
14 & 24 & 54 & 43 & $16(\mathrm{I})$ & $37(\mathrm{I})$ & $28(\mathrm{I})$ & $13(\mathrm{I})$ & $37(\mathrm{~S})$ & $35(\mathrm{R})$ & $\mathrm{d}$ & $\mathrm{d}$ & $\mathrm{d}$ \\
\hline
\end{tabular}

$\mathrm{I}=$ improved score (lower score than the occasion before).

$\mathrm{S}=$ stable score (same score or only one point difference).

$\mathrm{R}=$ reduced score (higher score than the occasion before).

- = drop out.

$\mathrm{d}=$ discharged.

symptoms and fewer difficulties in occupational performance do not seem to arise at the same time.

When analysing each assessment separately at item level some homogeneous trends could be seen, based on CPRSS-A. Symptoms of depression related to mood, feelings of unease, sleep, appetite, ability to concentrate, initiative, emotional involvement, pessimism, and zest for life all showed a positive trend during the treatment period. The same trend could not be seen for anxiety and obsession symptoms.

The occupational therapist rated most improvements for patients regarding the items of "Habituation" when using OCAIRS-S. The items "Skills" and "Environment" were mostly rated as stable. The items in OSA "Habituation" and "Volition" were the items that the patients themselves rated as giving them the most problems and also considered as most important for them to manage at the first occasion. However, "Habituation" was the item that had the most improvement during the treatment period referring to the patients' own ratings.

\section{Discussion}

The aim of the study was to describe recovering over time in occupational performance and affective symptoms for patients with depression. The sum score of CPRS-SA reflected an earlier improvement than the sum score of OCAIRS-S and OSA. The items in CPRS-S-A that describe depressive symptoms had a positive trend during the treatment period. However, this study indicates that even if the patients' affective symptoms improved after a while compared to the acute phase, it took time for the patients to resume their earlier occupational performance. This result adds a new perspective for patients with depression disorders, showing that occupational performance needs to be considered when discharge. Maybe the patient will need an extended period of occupational focused treatment. To support and enable occupational performance in order to manage activities of everyday life are important. There is, for example, evidence for that treatment for patients with mood disorders should include promotion of regularity in everyday activities as Grandin et al. stated in 2006 [21].

By the end of the treatment period this study showed more improvements with OSA, the self-rating assessment (8 of 14 patients), than by interviewing the patients with the OCAIRS-S (6 of 14 patients). This indicates that it is important to use more than one type of data collection method, such as interviewing and self-rating. This is in line with what Möller [22] argues regarding the multimethod data-collection approach in the treatment of patients with affective disorders. Möller also points out that different areas, such as medical symptoms and social functioning, should be measured. We argue that occupational performance must also be measured in order to understand patients with depressive disorders since occupational performance is affected.

The longitudinal design with repeated measures [10] applied in this study shows that it is necessary to gather data in clinical practice several times during a treatment period, since both occupational performance and affective symptoms varied during the period of four months for the patients in this study. For some of the patients, the variation showed a negative pattern. This should be considered since it will influence the content of the short-term goals and the offered interventions.

In the interview with OCAIRS-S and in the self-rating with OSA, habituation was the item most frequently rated as a problem and at the same time was considered as important to manage. At the end of the treatment, habituation was the item that had the most improvement but still problems existed. This also indicates the need for occupational focused treatment. Habituation influences significantly performance 
of activities in everyday life. Habituation forming the structure and routine of daily life, gives patterns for activities that influence the life style. Habituation holds together the patterns of occupations that give life its effectiveness and familiar character [9]. When there are difficulties in habits and routines for patients with psychiatric diagnoses they often need occupational therapy [23].

There were too few patients in the study to make any statistical calculations. The explorative nature of the study also confirmed that statistical tests were not suitable. There were variations in the investigated group concerning gender, age, and variation of sick leave. Even if 194 assessments were included in the study, no generalizing to larger or other populations should be made. The longitudinal design [10] gave a description of change in occupational performance and affective syndromes within each patient. The data collection at multiple time points gave a valuable understanding of each patient but also across patients. One limitation when using time series studies can be missing data. In the present study this occurred relatively few times and mainly for just two of the patients (patients 8 and 10).

This study is based on patients who received inpatient care in the beginning of their illness. This will influence the generalization of the result. People who received inpatient care have met the criteria for admission to a department; that is, the severity was of such a degree that outpatient treatment was judged not to be successful by the medical doctor. The degree of the severity may have influenced the time for improving on symptoms. In addition the small study group weakens generalization of the result.

A period of four months with data from four occasions was considered reasonable to analyse since eight of fourteen patients were discharged during a four-month period. Nevertheless a longer period would be of interest for future studies. In addition future studies including greater number of subjects and using a mixed methods design with quantitative and qualitative data will improve and deepen the knowledge in the area.

In conclusion this study indicates that reduced affective symptoms and fewer problems in occupational performance do not seem to arise at the same time. Consequently, occupational performance needs to be noticed when discharged from treatment caused by depression.

The result also suggests the importance of measuring on repeated occasions during the treatment period since this allows identification of the changes in occupational performance and affective symptoms for the patient and how these vary over time. The most affected item related to occupational performance was habituation, both in the interviews with OCAIRS-S and in the self-ratings with OSA. Habituation was the item that the patients themselves rated as giving the most problems and was also determined as most important for them to manage.

\section{Conflict of Interests}

The authors declare that there is no conflict of interests regarding the publication of this paper.

\section{References}

[1] Socialstyrelsen, October 2013, http://www.socialstyrelsen.se/.

[2] World Health Organization, 2013, http://www.who.int/en/.

[3] J.-O. Ottosson, Psykiatri, Liber AB, Stockholm, Sweden, 7th edition, 2009 (Swedish).

[4] American Psychiatric Association, Diagnostic and Statistical Manual of Mental Disorders 5 (DSM-5), American Psychiatric Association, Washington, DC, USA, 2013.

[5] D. Bilsker, M. Gilbert, T. Myette, and C. Stewart-Patteson, "Depression and work funktion: bridging the gap between mental health care and the workplace," in Occupational Therapy in Mental Health. A Vision for Participation, C. Brown and V. Stoffel, Eds., F.A. Davis Company, Philadelphia, Pa, USA, 2011.

[6] N. Spangler, "Mood disorders," in Occupational Therapy in Mental Health. A Vision for Participation, C. Brown and V. Stoffel, Eds., Davis Company, Philadelphia, Pa, USA, 2011.

[7] L. Haglund, E. Ekbladh, L.-H. Thorell, and I. R. Hallberg, "Practice models in Swedish psychiatric occupational therapy," Scandinavian Journal of Occupational Therapy, vol. 7, no. 3, pp. 107-113, 2000.

[8] S. W. Lee, R. Taylor, G. Kielhofner, and G. Fisher, "Theory use in practice: a national survey of therapists who use the model of human occupation," The American Journal of Occupational Therapy, vol. 62, no. 1, pp. 106-117, 2008.

[9] G. Kielhofner, Model of Human Occupation, Lippincott: Williams \& Wilkins, Baltimore, Md, USA, 4th edition, 2008.

[10] D. F. Polit and C. T. Beck, Nursing Research: Generating and Assessing Evidence for Nursing Practice, Lippincott Williams \& Wilkins, Philadelphia, Pa, USA, 8th edition, 2008.

[11] S. Deshpande, G. Kielhofner, C. Henriksson et al., A User's Manual for The Occupational Circumstances Assessment Interview and Rating Scale, Version 2.0, University of Illinois at Chicago, Chicago, Ill, USA, 2002.

[12] K. Baron, G. Kielhofner, A. Iyenger, V. Goldhammer, and J. Wolenski, A User's Manual for the Occupational Self Assessment (OSA), Version 2.2, University of Illinois at Chicago, 2006.

[13] P. Svanborg and M. Åsberg, "A new self-rating scale for depression and anxiety states based on the comprehensive psychopathological rating scale," Acta Psychiatrica Scandinavica, vol. 89 , no. 1, pp. 21-28, 1994.

[14] C. Henriksson and L. Haglund, Occupational Circumstance Assessment Interview and Rating Scale, Swedish Version 4.0, Department of Occupational Therapy, Faculty of Health Science, Linköping University, 2005.

[15] L. Haglund and C. Henriksson, "Testing a Swedish version of OCAIRS on two different patient groups," Scandinavian Journal of Caring Sciences, vol. 8, no. 4, pp. 223-230, 1994.

[16] J.-S. Lai, L. Haglund, and G. Kielhofner, "Occupational case analysis interview and rating scale-an examination of construct validity," Scandinavian Journal of Caring Sciences, vol. 13, no. 4, pp. 267-273, 1999.

[17] E. M. Hellsvik, Min Mening. Version 1.0. Swedish version of Occupational Self Assessment by Baron K, Kielhofner G, Iyenger A, Goldhammer V\& Wolenski J. Stockholm, Förbundet Sveriges Arbetsterapeuter, 2000.

[18] M. Åsberg, S. A. Montgomery, C. Perris, D. Schalling, and G. Sedvall, "CPRS: development and applications of a psychiatric rating scale," Acta Psychiatrica Scandinavica, supplement 271, pp. 5-32, 1978. 
[19] C. Holmstrand, G. Engström, and L. Träskman-Bendz, "Disentangling dysthymia from major depressive disorder in suicide attempters' suicidality, comorbidity and symptomatology," Nordic Journal of Psychiatry, vol. 62, no. 1, pp. 25-31, 2008.

[20] M. Mattila-Evenden, P. Svanborg, P. Gustavsson, and M. Åsberg, "Determinants of self-rating and expert rating concordance in psychiatric out-patients, using the affective subscales of the CPRS," Acta Psychiatrica Scandinavica, vol. 94, no. 6, pp. 386-396, 1996.

[21] L. D. Grandin, L. B. Alloy, and L. Y. Abramson, “The social zeitgeber theory, circadian rhythms, and mood disorders: review and evaluation," Clinical Psychology Review, vol. 26, no. 6, pp. 679-694, 2006.

[22] H. J. Möller, "Rating depressed patients: observer- vs selfassessment," European Psychiatry, vol. 15, no. 3, pp. 160-172, 2000.

[23] L. Haglund, L.-H. Thorell, and J. Wålinder, “Occupational functioning in relation to psychiatric diagnoses: schizophrenia and mood disorders," Nordic Journal of Psychiatry, vol. 52, no. 3, pp. 223-229, 1998. 


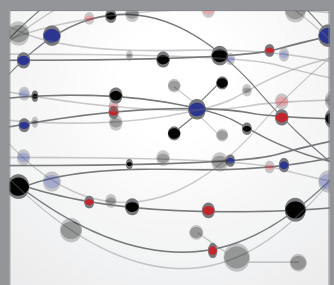

The Scientific World Journal
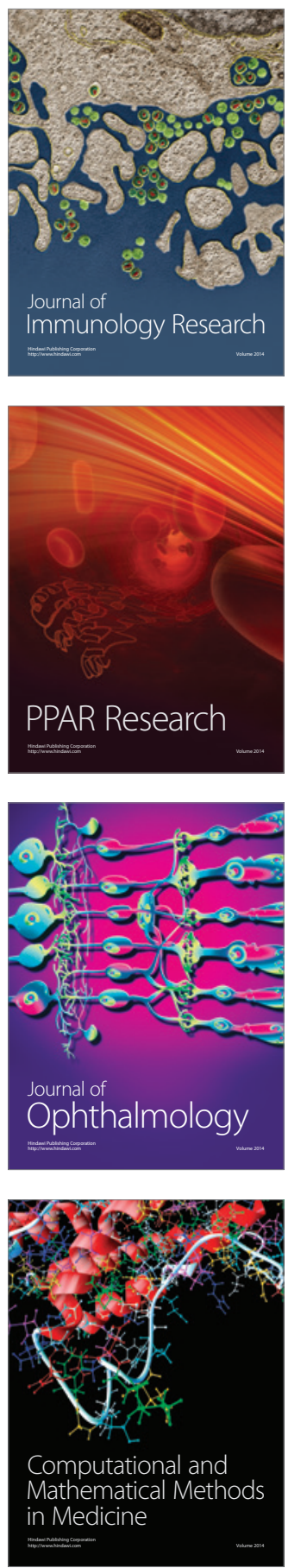

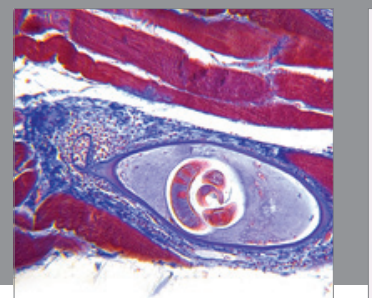

Gastroenterology

Research and Practice
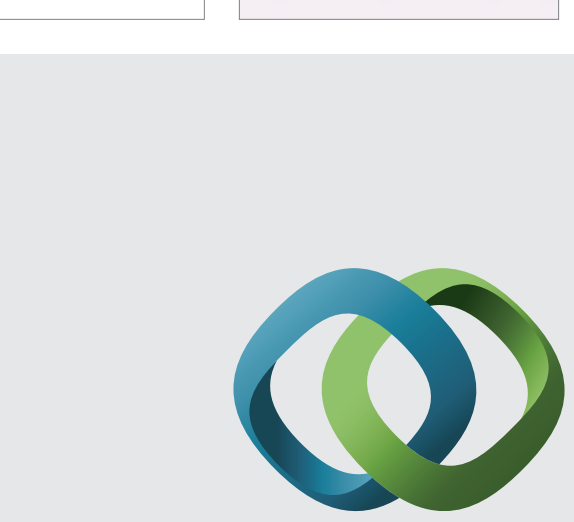

\section{Hindawi}

Submit your manuscripts at

http://www.hindawi.com
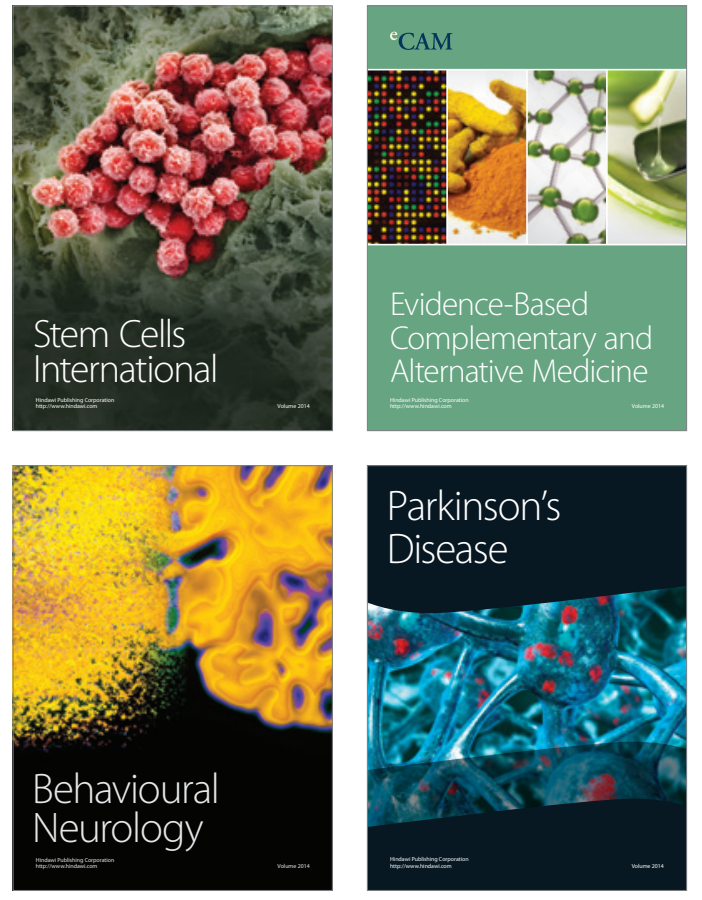
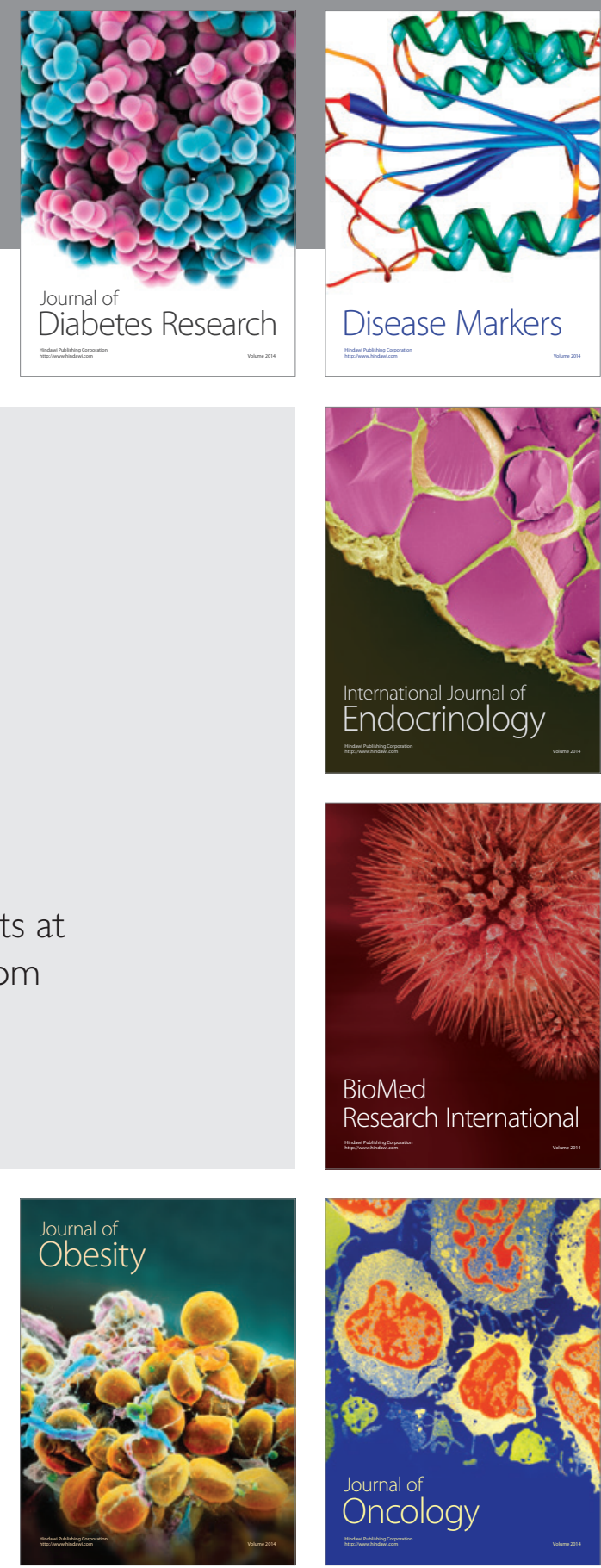

Disease Markers
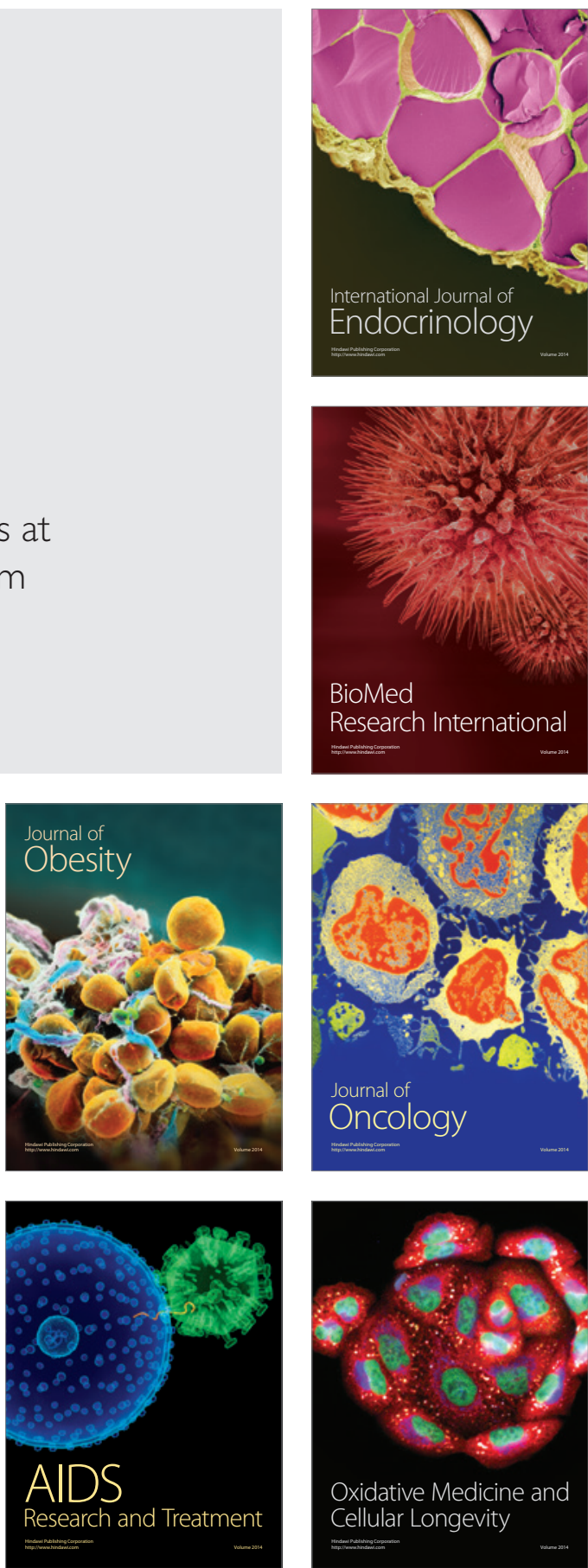